\title{
Sodium retention and hypertension with short dialysis
}

\author{
L SELLARS, V ROBSON, R WILKINSON
}

British Medical fournal, 1979, 1, 520-521

\section{Summary and conclusions}

Exchangeable sodium was measured in 26 patients undergoing dialysis with a modestly shortened schedule of 14.8 hours weekly and related to blood-pressure control. The group was compared with 27 patients studied in 1969 during twice-weekly dialysis totalling 22 hours, and with 18 patients studied in 1973 during dialysis of 18-21 hours weekly in three sessions. Exchangeable sodium was significantly increased with short dialysis compared with the other schedules and, although mean blood pressure was not significantly increased, significantly more patients required antihypertensive treatment than in either 1969 or 1973. A trend towards more frequent resort to bilateral nephrectomy than in 1973 did not reach significance.

Problems of hypertension and the side effects of its treatment, both medical and surgical, should be weighed against the social and economic advantages of short dialysis in deciding on the ideal schedule.

\section{Introduction}

In patients treated with long-term haemodialysis the major causes of death and disability are hypertensive heart disease, stroke, and coronary artery disease. ${ }^{1}$ Hypertension is an important risk factor in the second two conditions, and its presence has an important influence on the survival of patients receiving haemodialysis. ${ }^{2}$

The development of dialysers of larger surface area and of new membranes has increased dialysance rates and led to the use of shorter dialysis schedules. ${ }^{3}{ }^{4}$ These allow less time for ultrafiltration, with the possibility of an increase in body sodium and water and hence to an increase in blood pressure.

We decided to compare exchangeable sodium and mean arterial pressure in a group of patients currently receiving short dialysis schedules with values recorded in patients on longer schedules. ${ }^{5}$

\section{Patients and methods}

Twenty-six patients receiving regular thrice-weekly hospital dialysis in 1978 were studied. The mean duration of dialysis was 14.8 hours/week. The intended dialysate sodium concentration was $136 \mathrm{mmo}(\mathrm{mEq}) / 1$, and measured dialysate sodium $136 \cdot 8 \pm \mathrm{SD}$ $3.9 \mathrm{mmol} / \mathrm{l}$. Exchangeable sodium was measured during the 24 hours before dialysis. Blood pressure was the average of the recumbent predialysis pressures recorded over the two months before the day of measurement of exchangeable sodium. Bilateral nephrectomy was performed for hypertension when this persisted despite elimina-

Department of Nephrology, Freeman Hospital, Newcastle upon Tyne NE7 7DN

L SELLARS, $M B, M R C P$, registrar in medicine

V ROBSON, technician

R WILKINSON, MD, MRCP, consultant physician tion of salt and water overload by dialysis and dietary restriction and the use of maximum tolerated doses of antihypertensive agents.

Comparisons were made with the results of other studies in this department. In 1969, 27 patients were studied during twice-weekly dialysis for a total of 22 hours using dialysate containing $130 \mathrm{mmol}$ sodium/l. Seven of these patients were studied again four months after bilateral nephrectomy and these data substituted for their prenephrectomy measurements to form a group with the 20 patients not subjected to nephrectomy; together they constituted the "postnephrectomy" group, which was comparable to the 26 patients treated in 1978, of whom eight were subjected to nephrectomy, six because of hypertension. The "prenephrectomy" group in 1969 comprised the same patients but used the prenephrectomy exchangeable sodium and mean arterial pressure in the seven patients who underwent nephrectomy. ${ }^{6}$

In 1973,16 patients were studied during thrice-weekly dialysis totalling 18-21 hours against dialysate sodium concentrations of 130 and $136 \mathrm{mmol} / \mathrm{l}$ and two additional patients against only $136 \mathrm{mmol}$ sodium dialysate $/ 1.5$

In all studies patients were unselected except for proximity of their homes to the dialysis centre. All patients were receiving regular hospital dialysis. Dietary policy regarding salt intake did not change during the years covered by the study.

Lean body mass (LBM) was calculated from body weight, height, and skinfold thickness by the method of Edwards and Whyte." Exchangeable sodium was measured by the isotope dilution technique with $15 \mu \mathrm{Ci}{ }^{24} \mathrm{Na}$ and an equilibration period of 24 hours. Blood pressure was measured after five minutes of recumbency, diastolic pressure being recorded at the point of disappearance of sounds (phase V). Mean arterial pressure was calculated as diastolic pressure plus one-third of the pulse pressure.

At the end of dialysis the dialyser was rinsed into the patient with 1 litre $0 \cdot 9^{\circ}{ }_{0}$ saline.

Values are given as means $\pm 1 \mathrm{SD}$.

The mean age of patients in the present study was $42 \pm 11.75$ years; 17 were male and nine female. The mean duration of regular dialysis treatment was $41 \pm 35$ months.

In 1969 the Watson Marlow cuprophane $1 \mathrm{~m}^{2}$ Kiil dialyser was used. In 1973 the Meltec Multipoint cuprophane $1 \mathrm{~m}^{2}$ dialyser replaced it. In the present study the Meltec Multipoint and Rhone Poulenc $1 \mathrm{~m}^{2}$ polyacrylonitrile dialysers were used.

\section{Results}

In the 1978 group, eight patients had undergone bilateral nephrectomy, six for hypertension, one for infection, and one for bleeding. Eleven patients needed antihypertensive drugs. There was no significant correlation between mean arterial pressure and exchangeable sodium $(r=0.22 ; P>0 \cdot 2)$.

The table gives details of the groups studied in 1969, 1973, and 1978. Student's $t$ test was used in comparing exchangeable sodium and mean arterial pressures, the paired $t$ test being used when appropriate. Mean exchangeable sodium $(64.82 \pm 8.88 \mathrm{mmol} / \mathrm{kg} / \mathrm{LBM})$ was significantly higher than that measured in 1969 during twiceweekly dialysis or in 1973 with either 130 or $136 \mathrm{mmol}$ sodium dialysate $/ 1(P<0.01)$

Average mean arterial blood pressure $(104.8 \pm 12.8 \mathrm{~mm} \mathrm{Hg})$ was higher than that recorded in 1973 with more-prolonged dialysis, but the differences did not reach significance. Blood pressure was significantly lower in these patients (1978) than in the prenephrectomy 1969 group $(\mathbf{P}<0.02)$ but did not differ significantly from the more comparable postnephrectomy 1969 group $(P>0.4)$.

Fisher's exact test was used in comparing the proportion of patients subjected to bilateral nephrectomy and treated with antihypertensive drugs in the different periods studied. The bilateral nephrectomy rate for hypertension $(23 \%)$ was almost identical with that in 1969 and exceeded that in 1973, although the difference did not reach significance. The proportion of patients needing antihypertensive treatment with the current, shorter dialysis schedules $(42 \%)$ was 
Mean exchangeable sodium and mean arterial pressure in patients studied in 1969, 1973, and 1978. (Means expressed $\pm 1 S D$ )

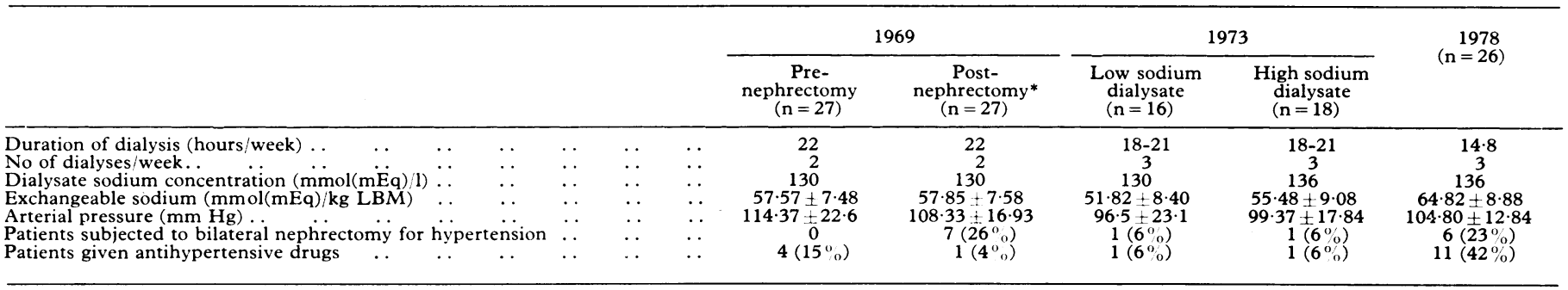

*Postnephrectomy group comprised 20 patients not requiring nephrectomy and seven subjected to this procedure.

significantly greater than in all other groups, including the prenephrectomy group studied in $1969(P=0.035)$. Details of antihypertensive treatment, exchangeable sodium, and mean arteria pressure for the 1978 group together with full statistical analysis will be supplied on request.

\section{Discussion}

We showed elsewhere that increasing the frequency of dialysis from twice to thrice weekly is accompanied by a reduction in exchangeable sodium and blood pressure. We have also found that increasing dialysate sodium from 130 to $136 \mathrm{mmol}(\mathrm{mEq}) / \mathrm{l}$ is accompanied by an increase in exchangeable sodium and mean arterial pressure. ${ }^{5}$ The increase in dialysate sodium concentration, however, was accompanied by a fall in the incidence of muscle cramps, and we are therefore reluctant to revert to low sodium dialysis in order to balance the reduction in ultrafiltration with short dialysis.

Our results show that current, shorter dialysis schedules, which are very popular with patients, are accompanied by large and statistically significant increases in exchangeable sodium. It is well established that sodium retention is an important factor in the hypertension of advanced renal disease, 89 and therefore not surprisingly hypertension is again becoming a problem in these patients. Although blood pressure in 1978 was not significantly higher than in 1973, and was lower than the values recorded in the 1969 postnephrectomy group, the proportion of patients needing bilateral nephrectomy had returned to the 1969 level, although because of the small numbers of patients concerned the increase over 1973, when the nephrectomy rate was very low, does not reach significance. There was also a significant increase in the proportion of patients needing antihypertensive drugs in 1978 compared with 1969 and 1973 . We have been unable to find a significant relation between exchangeable sodium and mean arterial pressure, probably because blood pressure is influenced by antihypertensive treatment and by renin in patients who have not had nephrectomy, as well as by sodium state. This is in keeping with our observation ${ }^{6}$ that a significant relation between exchangeable sodium and mean arterial pressure in patients receiving dialysis is seen only after bilateral nephrectomy, although a significant positive correlation has been shown in patients with advanced renal failure not requiring dialysis. ${ }^{10}$

In assessing short dialysis schedules, problems with control of blood pressure have not been emphasised. ${ }^{11}$ D'Amico et al ${ }^{3}$ reported good control of blood pressure in 205 patients with short dialysis, although $18.5 \%$ of patients required antihypertensive drugs. Similarly, $15 \%$ of patients in the series of Cambi et al required antihypertensive drugs and $2 \%$ bilateral nephrectomy for hypertension. In a comparison of long and short dialysis in two centres, Alvarez-Ude et $a l^{12}$ found that blood-pressure control was "good" in $94 \%$ of patients receiving long dialysis and $70 \%$ of patients on short dialysis. We did not attempt to compare the overall wellbeing of patients on short dialysis with that of patients on long dialysis, but Alvarez-Ude et al $^{12}$ found that patients on short dialysis schedules had a higher incidence of itching and symptoms of peripheral neuropathy but less dyspnoea and muscle weakness and higher haemoglobin values.

We have confirmed that there is an increased incidence of hypertension requiring treatment when dialysis is shortened and that this is likely to be due to increased body sodium. The economic and social advantages of short dialysis must be weighed against the risk of hypertension and the problems of antihypertensive treatment ${ }^{13}$ as well as the operative risks when bilateral nephrectomy is necessary and the worsening anaemia ${ }^{14}$ and occasional postural hypotension that may follow it. Possibly if the current, only modestly shortened dialysis schedule (mean 14.8 hours/week) were to be shortened further ${ }^{3}$ then hypertension would become a serious problem in some patients.

We thank Sister D Arnold and the nursing staff of the dialysis unit at Freeman Hospital for their collaboration in this study; Mrs R Grieveson for secretarial work; and Dr David Appleton for statistical advice.

Requests for reprints and details of antihypertensive treatment, exchangeable sodium, and mean arterial pressure for the 1978 group together with full statistical analysis may be obtained from: Dr L Sellars, Department of Medicine and Nephrology, Freeman Hospital, Freeman Road, High Heaton, Newcastle upon Tyne NE7 7DN.

\section{References}

1 Lazarus, J M, et al, Kidney International, 1975, 7, suppl, p 167.

2 Eliahou, H E, et al, Israel fournal of Medical Sciences, 1977, 13, 33.

${ }^{3}$ D'Amico, G, et al, in Proceedings of Sixth International Congress of Nephrology, p 629. Basle, Karger, 1976.

${ }^{4}$ Cambi, V, et al, Proceedings of the European Dialysis and Transplant Association, 1974, 11, 112

5 Wilkinson, R, Barber, S G, and Robson, V, Clinical Nephrology, 1977, 7, 101.

6 Wilkinson, R, et al, Quarterly fournal of Medicine, 1970, 39, 377.

${ }^{7}$ Edwards, K D G, and Whyte, H M, Clinical Science, 1959, 18, 361.

${ }^{8}$ Ledingham, J M, Fournal of the Royal College of Physicians of London, $1971,5,103$.

${ }^{9}$ Del Greco, F, et al, Kidney International, 1975, 7, suppl, p 176.

10 Dathan, J R E, Johnson, D B, and Goodwin, F J, Clinical Science and Molecular Medicine, 1973, 45, 77.

11 Martin, A M, et al, British Medical fournal, 1975, 3, 758.

12 Alvarez-Ude, F, et al, Proceedings of the European Dialysis and Transplant Association, 1976, 12, 606.

${ }^{13}$ Hull, A R, et al, Kidney International, 1975, 7, suppl, p 184.

14 Nilman, N, Acta Medica Scandinavica, 1974, 195, 479.

(Accepted 15 fanuary 1979) 